
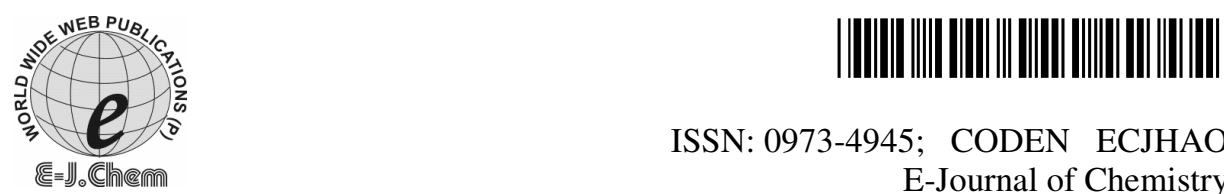

ISSN: 0973-4945; CODEN ECJHAO

E-Journal of Chemistry

http://www.e-journals.net

Vol. 5, No.3, pp. 521-528, July 2008

\title{
Studies on the Influence of Monomers on the Performance Properties of Epoxy Acrylate Resin
}

\author{
AMRITA SHARMA*, DEVENDRA AGARWAL and JAGABIR SINGH ${ }^{\#}$ \\ Department of Oil \& Paint Technology, \\ Harcourt Butler Technological Institute, Kanpur 208002, UP, India \\ \#Jubilant Organosys Ltd. Plot 1A, Sector 16, Noida - 201301 \\ sharma_amrita@rediffmail.com; Fax No. +915122501541
}

Received 3 December 2007; Accepted 1 January 2008

\begin{abstract}
Twelve blend samples were prepared by physical mixing of epoxy acrylate resins with various monomers viz. ethoxylated phenol monoacrylate (EOPA), tripropylene glycol diacrylate (TPGDA) and trimethylol propane tri acrylate(TMPTA), having weight ratio of epoxy acrylate resin and monomers are 50:50, 60:40, 70:30, 80:20. These samples were cured under UV radiation using $5 \%$ photo initiator by weight. These blends were evaluated for mechanical, chemical \& thermal properties. It was found that the sample having mono \& tri functional monomers shows better properties than the samples having di functional monomer.
\end{abstract}

Keywords: Epoxy acrylate, UV radiation, Monomers, Performance properties, Chemical resistance.

\section{Introduction}

Photo-initiated curing reactions are powerful processes to quickly create highly cross-linked polymer networks by supplying an appropriate form of energy, generally ultraviolet (UV) light, to a thermosetting material like epoxy, unsaturated polyester, acrylic resins etc., containing photo initiating species ${ }^{1-5}$

In recent years, epoxy acrylate prepolymer suitable for use in ultraviolet (UV) curing systems, command the largest use in the market and are typically used in applications ranging from paper and card over-print varnishes, wood coatings, screen and lithographic inks and solder resist inks for printed circuit boards ${ }^{6-9}$. Other areas such as vacuum metallizing base coatings, adhesive laminates, release coatings and video disc coatings are also becoming more important ${ }^{10}$ Epoxy acrylates are noted for adhesive properties, flexibility, nonyellowing, hardness, and chemical resistance ${ }^{11-13}$. The epoxy backbone promotes tough-ness and flexibility to cured films whilst the carbon-carbon and ether bonds of the same improve the chemical resistance. The epoxy acrylate resins have the merits of: (a) high reactivity (b) possibility of structural variation in backbone (e.g. bisphenol A or epoxy novolacs) ${ }^{14-16}$ which provides good coating properties after curing and (c) excellent adhesion performance (due to 
the presence of pendant hydroxyl groups). However, the UV cured films based on epoxy diacrylate as oligomer are very brittle and the relative elongation at break is very low ${ }^{17-19}$. The epoxy acrylate resin can further be cross linked with different functionality monomers to change or modify its performance. These acrylic monomers are the essential part of every UV/EB formulation. Nevertheless, there are only a few studies published explaining the underlying logic of explaining the use of acrylic monomers. In the past experimental works, trimethylolpropane triacrylate (TMPTA) has been used by various researchers ${ }^{20,21}$.

Therefore, for the first time we tried to prepare a blend by physical mixing of epoxy acrylate resin with mono, di \& tri functional monomers and studied the effect by using different concentration of these monomers.

\section{Experimental}

\section{Materials}

Epoxy resin (M/s Parik Resin), acrylic acid (M/s E. Merck), triethylamine (M/s E. Merck), ethoxylated phenol monoacrylate (M/s Cognis), tripropylene glycol diacrylate (M/s Cognis), trimethylol propane triacrylate ((M/s Cognis), Darocure 1173 (M/S Ciba Specialty Chemical), Ethyl alcohol (Ranbaxy Laboratories Ltd.), $\mathrm{NaOH}$ (M/s E. Merck), $\mathrm{H}_{2} \mathrm{SO}_{4}$ (M/s S. D. Fine Chemicals) were used during the investigation.

\section{Preparation of epoxy acrylate resin}

A general purpose, bisphenol a based epoxy resin (EEW: 180), acrylic acid and triethyl amine were used for the synthesis of epoxy acrylate resin. The epoxy acrylate resin was synthesized by reacting epoxy resin and acrylic acid in 1:1 mole ratio. Tri ethylamine was used as a catalyst. The acid value of prepared resin was $3.0 \mathrm{mg} \mathrm{KOH} / \mathrm{gm}$ solid as shown in Scheme 1.

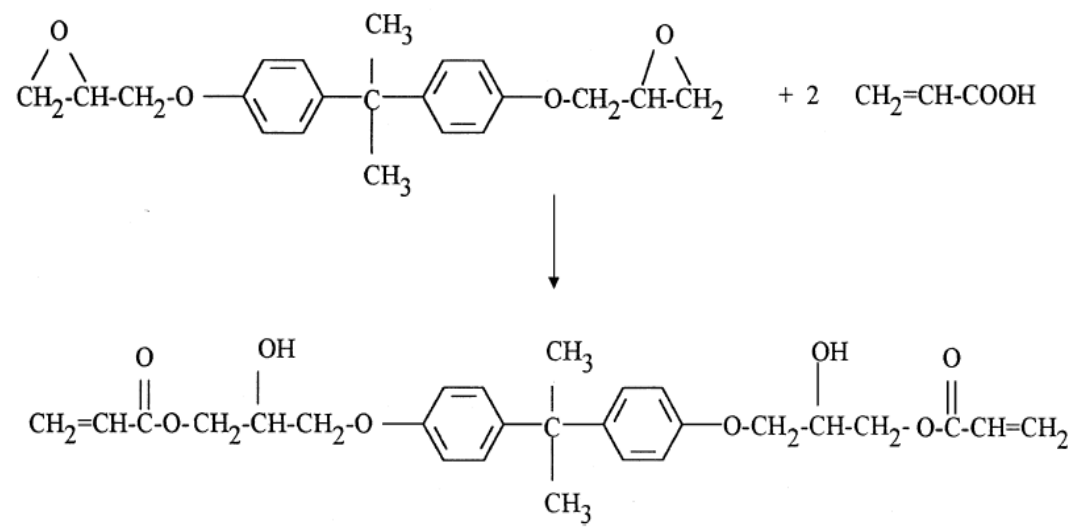

Scheme 1

\section{Preparation of blends of epoxy acrylate \& monomers}

Epoxy acrylate resin was physically mixed with different monomers of different concentration with an interval of $10 \mathrm{wt}$. \%. All the samples were designated as shown in Table 1.

\section{Curing of blend samples}

The blend samples with 5 wt. \% photo initiator [Darocure 1173] were cured in a UV Oven at a speed of 10 meter per minute in atmospheric air with 80 watts $/ \mathrm{cm}$ mercury vapor bulb. 
Table 1. Sample designation of various blend samples

\begin{tabular}{cccccc}
\hline S. No. $\begin{array}{c}\text { Epoxy Acrylate, } \\
\text { Wt. } \%\end{array}$ & $\begin{array}{c}\text { EOPA, } \\
\text { Wt. } \%\end{array}$ & $\begin{array}{c}\text { TPGDA, } \\
\text { Wt. } \%\end{array}$ & $\begin{array}{c}\text { TMPTA, } \\
\text { Wt. } \%\end{array}$ & $\begin{array}{c}\text { Sample } \\
\text { Designation }\end{array}$ \\
\hline 1 & 50 & 50 & 0 & 0 & $\mathrm{R}_{1} \mathrm{M}_{1}$ \\
2 & 60 & 40 & 0 & 0 & $\mathrm{R}_{1} \mathrm{M}_{2}$ \\
3 & 70 & 30 & 0 & 0 & $\mathrm{R}_{1} \mathrm{M}_{3}$ \\
4 & 80 & 20 & 0 & 0 & $\mathrm{R}_{1} \mathrm{M}_{4}$ \\
5 & 50 & 0 & 50 & 0 & $\mathrm{R}_{1} \mathrm{D}_{1}$ \\
6 & 60 & 0 & 40 & 0 & $\mathrm{R}_{1} \mathrm{D}_{2}$ \\
7 & 70 & 0 & 30 & 0 & $\mathrm{R}_{1} \mathrm{D}_{3}$ \\
8 & 80 & 0 & 20 & 0 & $\mathrm{R}_{1} \mathrm{D}_{4}$ \\
9 & 50 & 0 & 0 & 50 & $\mathrm{R}_{1} \mathrm{~T}_{1}$ \\
10 & 60 & 0 & 0 & 40 & $\mathrm{R}_{1} \mathrm{~T}_{2}$ \\
11 & 70 & 0 & 0 & 30 & $\mathrm{R}_{1} \mathrm{~T}_{3}$ \\
12 & 80 & 0 & 0 & 20 & $\mathrm{R}_{1} \mathrm{~T}_{4}$ \\
\hline
\end{tabular}

${ }^{a} R:$ Epoxy Acrylate, $M:$ EOPA, $D: T P G D A, T: T M P T A$

\section{Preparation of panels}

The blend samples were applied on sand blasted steel panels of size $150 \times 100 \times 1.25 \mathrm{~mm}$ with a bar applicator (M/s Sheen Instruments Ltd., U.K.). A dry film thickness of about 10$15 \mu$ was maintained on all the panels. The films were cured as per the cure schedule discussed earlier.

\section{Mechanical properties}

\section{Adhesion}

The adhesion properties of the cured films were evaluated by cross - cut adhesion test method. In this test, parallel cut were made on the coating in two directions to form a series of small squares, originally one hundred of them, $1.25 \mathrm{~mm}$ in size. An adhesive tape was applied to the cross cuts, the tape was rolled at the place to assure good adhesion, and then removed with a force perpendicular to the coated substrate. The number of squares removed, gave the numerical value of its adhesiveness.

\section{Impact resistance of cured film}

The impact resistance of the cured film samples was evaluated by dropping a hemispherical shaped 2-Lb weight from different heights, ranging from 25 to 15 inches (DEF1053 specification). The tests were carried out on the uncoated side of the panels facing the falling weight.

\section{Pencil hardness}

As per the specification in ASTM D3363, pencil hardness of the cured films was determined by using a calibrated set of drawing leads ranging from $6 \mathrm{~B}$, the softest, to $6 \mathrm{H}$, the hardest. The first pencil that scratches out the coating from the substrate was reported as the coating's hardness.

\section{Chemical properties}

The panels were also examined for a visual change in the film by conducting spot test with different chemicals like $\mathrm{H}_{2} \mathrm{SO}_{4}(10 \%$ Sol.), $\mathrm{NaOH}$ (10\% Sol.) \& Toluene etc. for $24 \mathrm{~h}$ at ambient temperature. 


\section{Thermal Properties}

The thermal stability of the blend samples was determined by comparing the onset degradation temperature (up to 5\% wt. loss) of the cured samples with Thermogravimetric analyzer (TGA) of Universal V3.9A TA instrument, at a heating rate of $20^{\circ} \mathrm{C} / \mathrm{min}$. in nitrogen atmosphere from 50 to $600^{\circ} \mathrm{C}$.

\section{Results and Discussions}

\section{Adhesion, Impact resistance \& Pencil hardness of cured film of blend samples}

Table 2 shows the surface properties of the cured film of different blends samples. The table indicates that except $R_{1} D_{1}, R_{1} D_{2}, R_{1} D_{3}$, and $R_{1} D_{4}$, all the blend samples pass through adhesion test. The blend samples with EOPA \& TMPTA shows improved adhesion \& pencil hardness which is due to the very bulky side group present in EOPA, directly linked to the polymeric network, limiting the freedom of movement of this network. Whereas in TMPTA, the polarity of the linkage group gives more degree of dipolar interaction which leads to better mechanical properties. The TPGDA shows inferior mechanical properties except impact resistance as compared to EOPA \& TMPTA. This is due to the higher freedom of movement around the linkage, enabling the stretch with the polarity, giving dipolar interaction which is responsible for mechanical properties.

Table 2. The surface properties of the cured film of different blends samples.

\begin{tabular}{cccc}
\hline \multirow{2}{*}{ Sample code } & \multicolumn{3}{c}{ Mechanical properties of paint films } \\
\cline { 2 - 4 } & Adhesion* & Impact resistance, inches & Pencil hardness \\
\hline $\mathrm{R}_{1} \mathrm{M}_{1}$ & 2 & 25 & $3 \mathrm{H}$ \\
$\mathrm{R}_{1} \mathrm{M}_{2}$ & 2 & 25 & $4 \mathrm{H}$ \\
$\mathrm{R}_{1} \mathrm{M}_{3}$ & 1 & 25 & $5 \mathrm{H}$ \\
$\mathrm{R}_{1} \mathrm{M}_{4}$ & 1 & 20 & $5 \mathrm{H}$ \\
$\mathrm{R}_{1} \mathrm{D}_{1}$ & 5 & 25 & $\mathrm{HB}$ \\
$\mathrm{R}_{1} \mathrm{D}_{2}$ & 4 & 25 & $\mathrm{H}$ \\
$\mathrm{R}_{1} \mathrm{D}_{3}$ & 3 & 25 & $\mathrm{H}$ \\
$\mathrm{R}_{1} \mathrm{D}_{4}$ & 3 & 25 & $2 \mathrm{H}$ \\
$\mathrm{R}_{1} \mathrm{~T}_{1}$ & 2 & 10 & $5 \mathrm{H}$ \\
$\mathrm{R}_{1} \mathrm{~T}_{2}$ & 2 & 15 & $5 \mathrm{H}$ \\
$\mathrm{R}_{1} \mathrm{~T}_{3}$ & 1 & 15 & $5 \mathrm{H}$ \\
$\mathrm{R}_{1} \mathrm{~T}_{4}$ & 1 & 15 & $5 \mathrm{H}$ \\
\hline
\end{tabular}

$* 1=$ No removal of paint film; $2=5-20 \%$ removal of paint film; $3=20-50 \%$ removal of paint film;

$4=50-80 \%$ removal of paint $5=80-100 \%$ removal of paint film

Comparative acid, alkali \& solvent resistance of epoxy acrylate modified with different monomers \& their different concentrations cured under UV-Radiation

Table 3 shows the comparative acid, alkali \& solvent resistance of cured film blends. A quick perusal of Table 3 signifies that the coating film prepared with TMPTA offered maximum resistance towards acid, alkali \& solvent, as compared to the film of other monomers. This behavior is due to the high reactivity of TMPTA, which results in a more complex structure, resulting better resistance as compared to other samples.

\section{Thermal properties}

The system was evaluated for thermal stability in nitrogen atmosphere by thermogravimetric analysis. The thermogravimetric (TG) traces were obtained for samples $R_{1} M_{1}, R_{1} D_{1} \& R_{1} T_{1}$ which are shown in Figures 2, $3 \& 4$ respectively. The experimental data obtained at initial $\left(T_{i}\right)$, 
peak $\left(\mathrm{T}_{\mathrm{p}}\right)$ and final $\left(\mathrm{T}_{\mathrm{f}}\right)$ decomposition temperature as well as char residue at $445{ }^{\circ} \mathrm{C}$ derived from the traces are given in Table 4 . Figures $2,3 \& 4$ clearly indicate that both $R_{1} M_{1} \& R_{1} D_{1}$ samples show two step mass loss in $T G$ traces while the $R_{1} T_{1}$ sample show single step mass loss. The improved resistance to thermo-oxidative degradation may possibly be due to the high cross link density of $R_{1} T_{1}$ blend sample. The char yield was also higher in sample $R_{1} T_{1}$ than other samples. This is due to the limited cross linking in other samples.

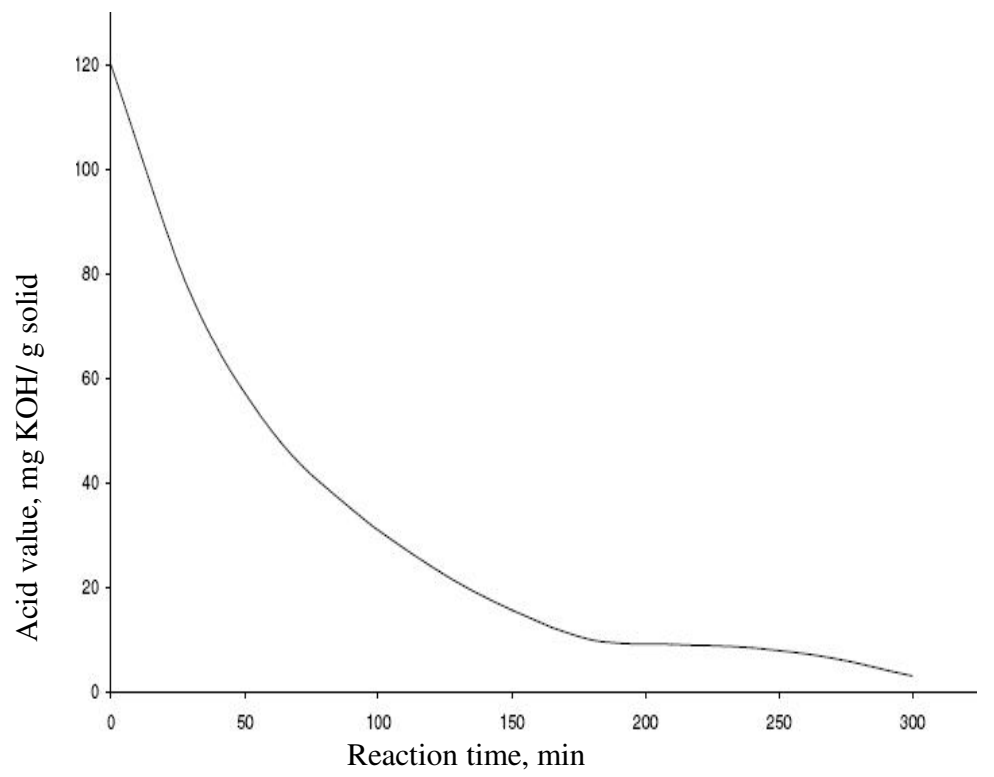

Figure 1. Acid value versus reaction time

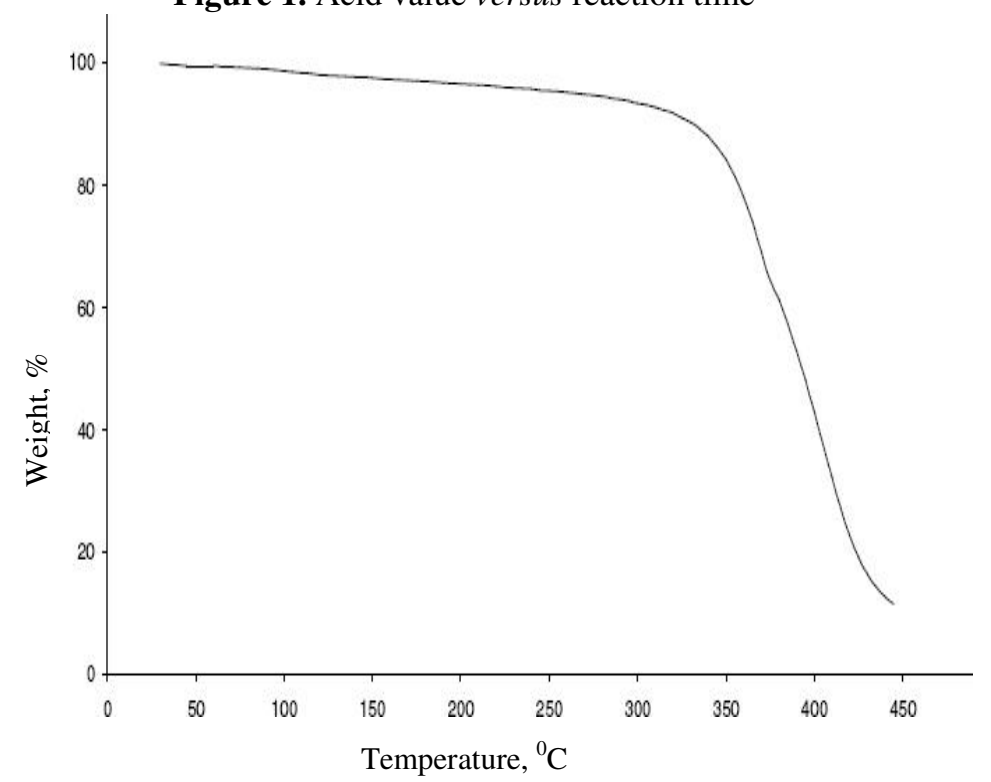

Figure 2. TGA traces of epoxy acrylate with EOPA ( sample R1M1) 


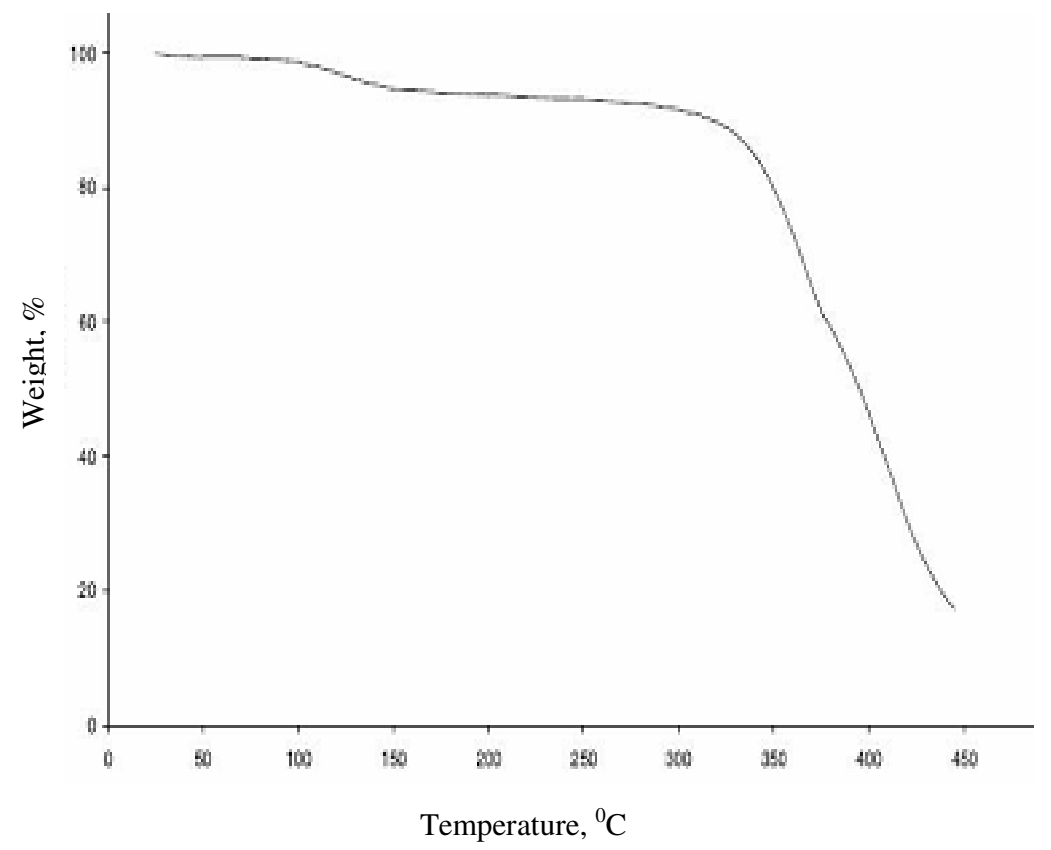

Figure 3. TGA traces of eopoxy acrylate with TPGDA (sample $R_{1} D_{1}$ )

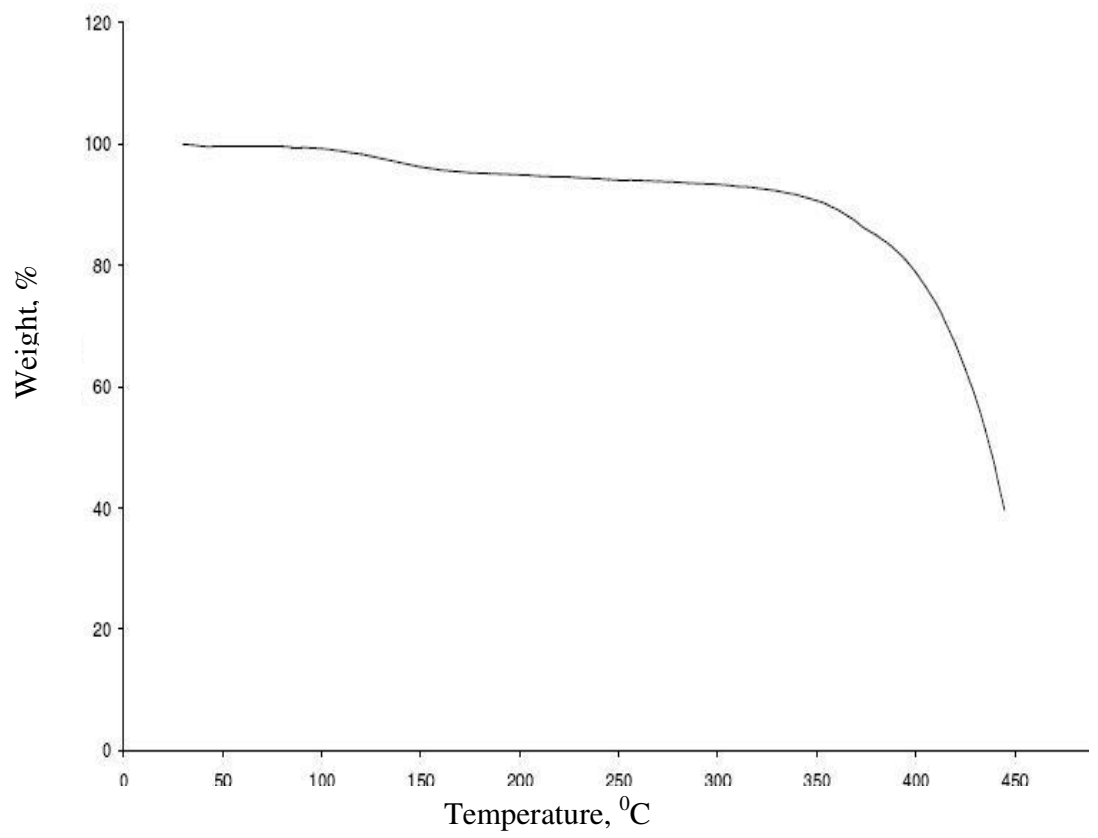

Figure 4. TGA traces of eopoxy acrylate with TMPTA (sample $\mathrm{R}_{1} \mathrm{~T}_{1}$ ) 
Table 3. The comparative acid, alkali \& solvent resistance of cured film blends

\begin{tabular}{cccc}
\hline \multirow{2}{*}{ Sample code } & \multicolumn{3}{c}{ Chemical properties of paint films } \\
\cline { 2 - 4 } & $\mathrm{H}_{2} \mathrm{SO}_{4}$, & NaOH & Toluene \\
\hline $\mathrm{R}_{1} \mathrm{M}_{1}$ & Fail & Fail & Pass \\
$\mathrm{R}_{1} \mathrm{M}_{2}$ & Pass & Pass & Pass \\
$\mathrm{R}_{1} \mathrm{M}_{3}$ & Pass & Pass & Pass \\
$\mathrm{R}_{1} \mathrm{M}_{4}$ & Pass & Pass & Pass \\
$\mathrm{R}_{1} \mathrm{D}_{1}$ & Pass & Pass & Fail \\
$\mathrm{R}_{1} \mathrm{D}_{2}$ & Pass & Pass & Fail \\
$\mathrm{R}_{1} \mathrm{D}_{3}$ & Pass & Pass & Pass \\
$\mathrm{R}_{1} \mathrm{D}_{4}$ & Pass & Pass & Pass \\
$\mathrm{R}_{1} \mathrm{~T}_{1}$ & Pass & Pass & Pass \\
$\mathrm{R}_{1} \mathrm{~T}_{2}$ & Pass & Pass & Pass \\
$\mathrm{R}_{1} \mathrm{~T}_{3}$ & Pass & Pass & Pass \\
$\mathrm{R}_{1} \mathrm{~T}_{4}$ & Pass & Pass & Pass \\
\hline
\end{tabular}

Table 4. Thermal behavior of isothermally cured blends of Epoxy acrylate resin / monomers (heating rate $20^{\circ} \mathrm{C} / \mathrm{min}$.)

\begin{tabular}{|c|c|c|c|c|c|c|c|c|c|}
\hline \multirow[b]{2}{*}{ Code } & \multicolumn{4}{|c|}{ I Stage } & \multicolumn{4}{|c|}{ II Stage } & \multirow[b]{2}{*}{ Char yield } \\
\hline & $\begin{array}{l}\mathrm{T}_{0} \\
{ }^{0} \mathrm{C}\end{array}$ & $\begin{array}{l}\mathrm{T}_{\mathrm{p}} \\
{ }^{0} \mathrm{C}\end{array}$ & $\begin{array}{l}\mathrm{T}_{\mathrm{F}} \\
{ }^{0} \mathrm{C}\end{array}$ & $\begin{array}{c}\text { Mass } \\
\text { loss, \% }\end{array}$ & $\begin{array}{l}\mathrm{T}_{0} \\
{ }^{0} \mathrm{C}\end{array}$ & $\begin{array}{l}\mathrm{T}_{\mathrm{p}} \\
{ }^{0} \mathrm{C}\end{array}$ & $\begin{array}{l}\mathrm{T}_{\mathrm{F}} \\
{ }^{0} \mathrm{C}\end{array}$ & $\begin{array}{l}\text { Mass } \\
\text { loss, \% }\end{array}$ & \\
\hline $\mathrm{R}_{1} \mathrm{M}_{1}$ & 260 & 351.1 & 370 & 27.4 & 375 & 423 & 445 & 82.2 & 11.46 \\
\hline $\mathrm{R}_{1} \mathrm{D}_{1}$ & 145 & 350 & 380 & 37.3 & 385 & 435 & 445 & 69.4 & 17.29 \\
\hline $\mathrm{R}_{1} \mathrm{~T}_{1}$ & 190 & 422 & 445 & 58.3 & & & & & 39.58 \\
\hline
\end{tabular}

\section{Conclusion}

From the preceding results \& discussions it can be concluded that the films of blend sample containing EOPA \& TMPTA shows better adhesion, hardness, chemical resistance \& thermal resistance properties as compared to TPGDA. Epoxy acrylate resin containing EOPA \& TMPTA can be used in harsh environment such as automotives and it is also suitable for metal coating at ambient temperature. As Epoxy acrylate resin containing TPGDA has high impact resistance so it can be used as an oligomer in UV-cured coatings for plastic instead of flexible urethane acrylate.

\section{References}

1. Shi W, Ranby B, J Appl Polym Sci, 1994, 51, 1129-1139.

2. Dakin VI, J Appl Polym Sci, 1996, 59,1355-1363.

3. Andrzejewska E and Andrzejewska M, J Polym Sci Pol Chem, 1998, 36, 665-673.

4. $\quad$ Bajpai M, Shukla V and Kumar A, Prog Org Coat, 2002, 44, 271-278.

5. Abadie MJM, Xiong Y and Boey FYC, Eur Polym J, 2003, 39,1243-1247.

6. Holman R and Oldring P, UV and EB curing formulation for printing inks, coatings and paints. SITA Technology, 1988.

7. (a) Hourston DJ and Zia Y, J Appl Polym Sci 1984, 29, 629; (b) Elsabee M Z, Dror M, Berry G C, J Appl Polym Sci, 1983, 28, 2151.

8. Elsabee M Z, Dror M, Berry G C, J Appl Polym Sci,1983, 28, 2151. 
9. Cassidy EF, Xiao HX, Frisch KC and Frisch HL, J Polym Sci: Polym Chem Ed 1984, 22, 2667.

10. Costanza J, Silveri A, Vana J. Federation of Societies of Coatings Technology, 1986.

11. Ro.ey C, Photopolymerisation of surface coatings. New York: Wiley, 1982.

12. Ketley DA and Toao H J, J Radiation Curing, 1979, April 22.

13. Perkins CW. J Radiation Curing 1981; January 16.

14. Opera S, Vlad S, Stanciu A, and Macoveanu M, Eur. Polym. J. 2003, 36, 373.

15. Bajpai M, Shukla V, and Kumar A, Prog. Org. Coat. 2002, 44, 271.

16. Chattophadyay D K, Panda S S, Raju K V S N, Prog. Org. Coat, 2005, 54 (1), 10.

17. Idriss Ali K M, Mubarak A K, Mokhlesur R and Mahmuda G, J. Appl. Polym. Sci. 1997, 66, 1997-2004.

18 Kim.B K and Paik S H, J. Appl. Polym. Sci. Part A: Polym Chem. 1999, 37, 2703.

19. Rayss J, Podkscielny W M and Wodomski, J, J. Appl. Polym. Sci., 1993,49, 835.

20. Khan Mubarak A, Tasneen S S, Habib M Ahsan and Rahman M Mizanur, Polymer Radiation Engineering, 2004, 43, 301-308.

21. Chattopadhyay D K, Siva Sankar Panda and Raju KVSN, Progress in organic coating, 2005, 54, 10-19. 


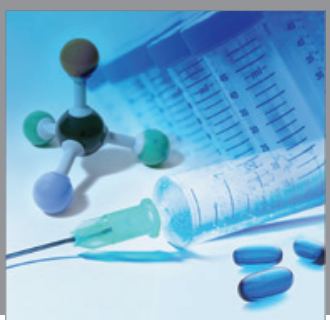

International Journal of

Medicinal Chemistry

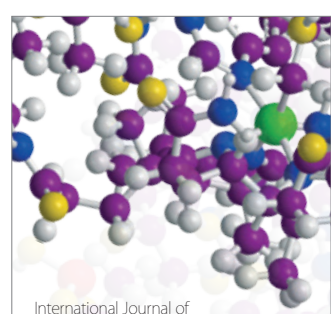

Carbohydrate Chemistry

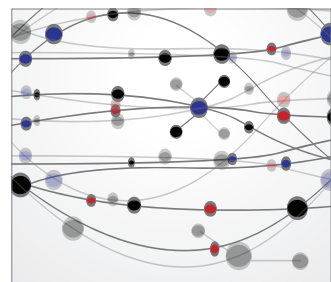

The Scientific World Journal
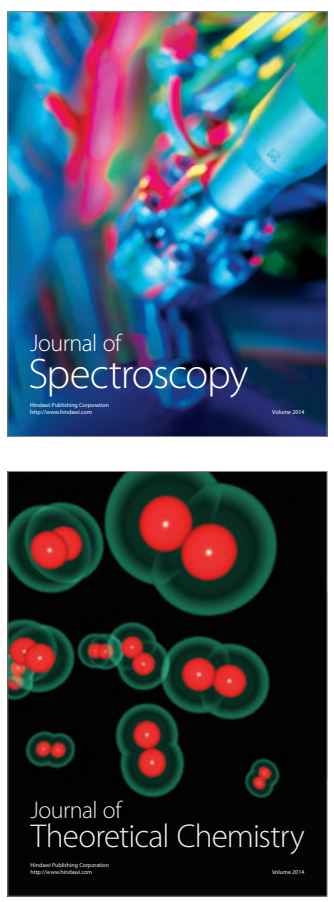
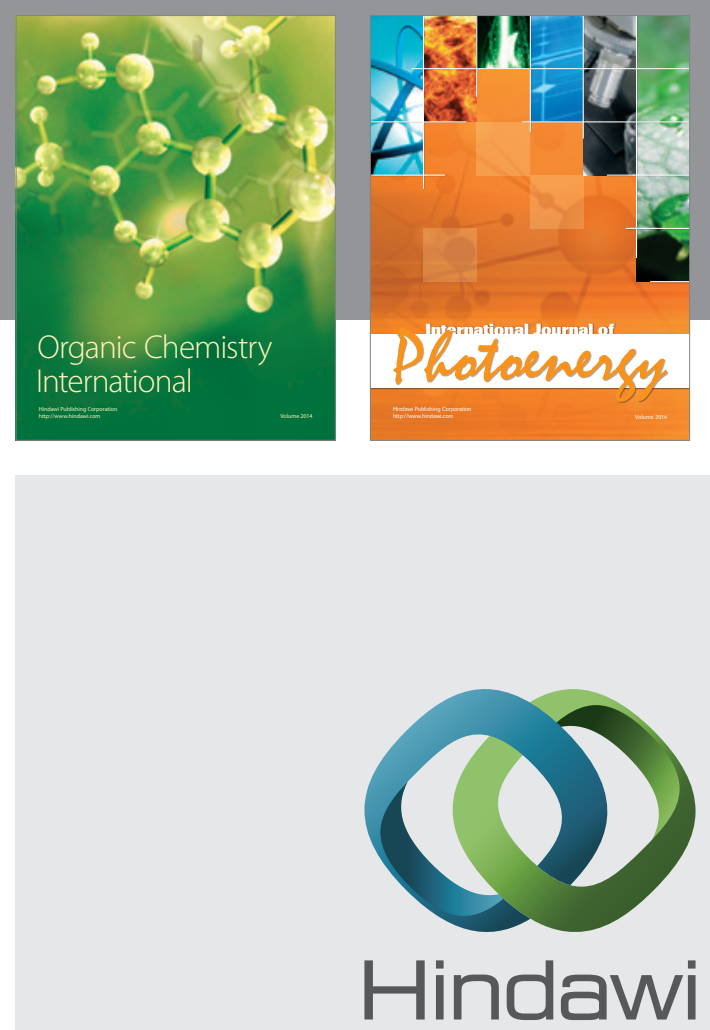

Submit your manuscripts at

http://www.hindawi.com
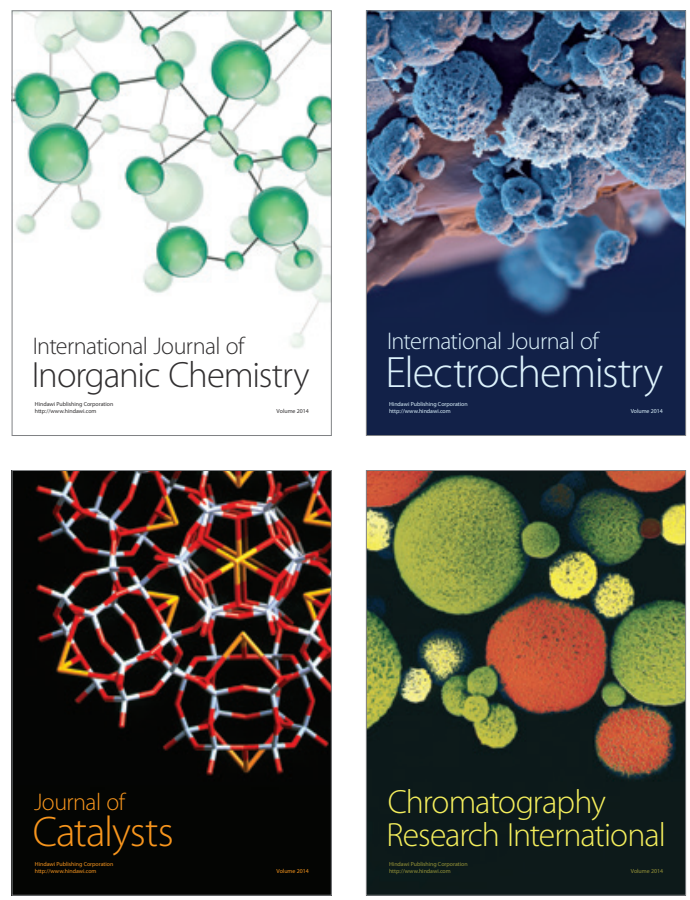
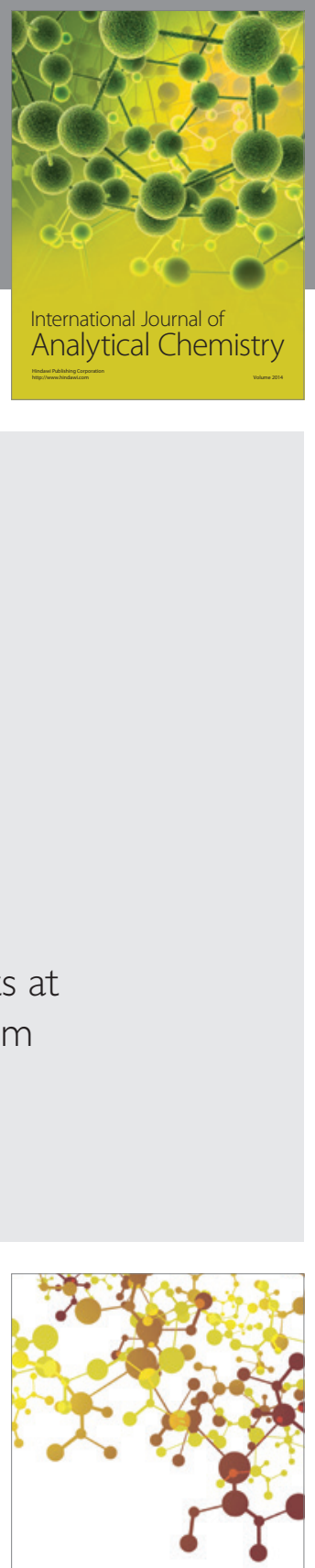

Journal of

Applied Chemistry
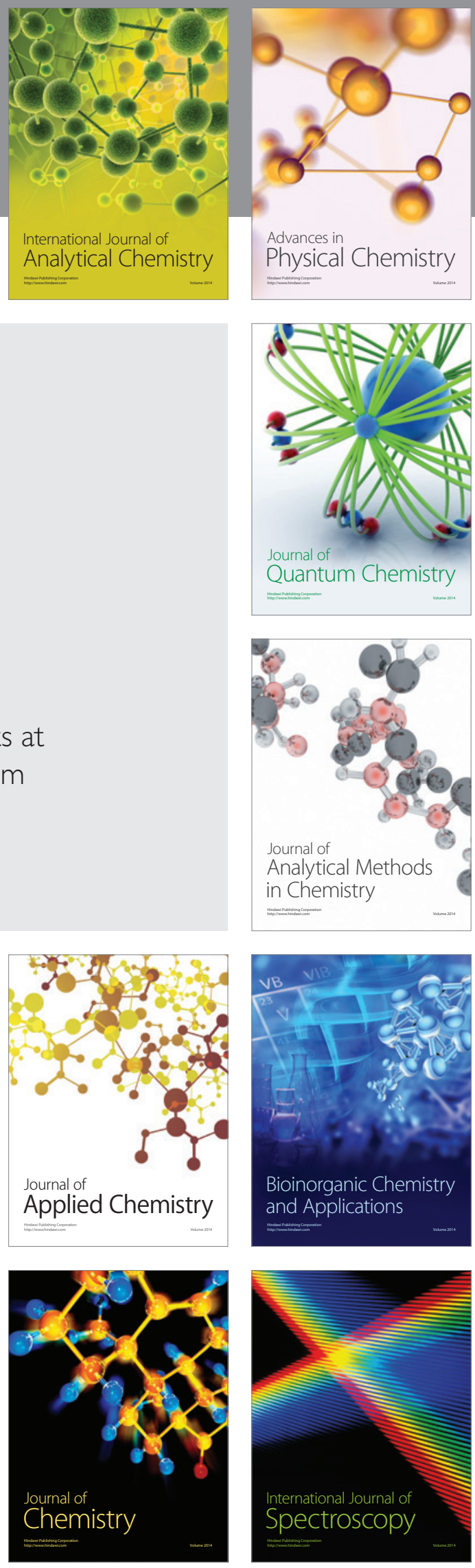